\title{
The Relations Between Auditory Processing Scores and Cognitive, Listening and Reading Abilities
}

DOI:

10.1097/AUD.0000000000000984

\section{Document Version}

Accepted author manuscript

Link to publication record in Manchester Research Explorer

\section{Citation for published version (APA):}

Seeto, M., Tomlin, D., \& Dillon, H. (2021). The Relations Between Auditory Processing Scores and Cognitive, Listening and Reading Abilities. Ear and hearing, Publish Ahead of Print.

https://doi.org/10.1097/AUD.0000000000000984

\section{Published in:}

Ear and hearing

\section{Citing this paper}

Please note that where the full-text provided on Manchester Research Explorer is the Author Accepted Manuscript or Proof version this may differ from the final Published version. If citing, it is advised that you check and use the publisher's definitive version.

\section{General rights}

Copyright and moral rights for the publications made accessible in the Research Explorer are retained by the authors and/or other copyright owners and it is a condition of accessing publications that users recognise and abide by the legal requirements associated with these rights.

\section{Takedown policy}

If you believe that this document breaches copyright please refer to the University of Manchester's Takedown Procedures [http://man.ac.uk/04Y6Bo] or contact uml.scholarlycommunications@manchester.ac.uk providing relevant details, so we can investigate your claim.

\section{OPEN ACCESS}


1 The relations between auditory processing scores and cognitive, listening and reading

2 abilities

3 Mark Seeto $^{1}$, Dani Tomlin ${ }^{2}$, Harvey Dillon ${ }^{3,4}$

$4 \quad{ }^{1}$ National Acoustic Laboratories, Sydney, Australia.

$5{ }^{2}$ Department of Audiology and Speech Pathology, The University of Melbourne, Melbourne, 6 Australia.

$7 \quad{ }^{3}$ Department of Linguistics, Macquarie University, Sydney, Australia.

$8{ }^{4}$ Manchester Centre for Audiology and Deafness, School of Health Sciences, The University 9 of Manchester, Manchester, United Kingdom.

10

11 Financial disclosures/conflicts of interest: Funding for this project was provided by the HEARing Cooperative Research Centre, an Australian Government initiative. There are no conflicts of interest.

Correspondence should be addressed to:

Mark Seeto, National Acoustic Laboratories, Level 5, 16 University Avenue, Macquarie 
27 Objective: To investigate associations between auditory processing abilities, cognitive abilities, listening ability and reading ability in children.

29

Design: This was a cross-sectional study involving 155 children (105 referred for auditory processing assessment and 50 with no reported listening concerns) aged between 7 and 13 years. Each child was assessed on auditory processing tests, cognitive tests and a reading test. Additional data on reading ability was provided by the reading score from a national test. Questionnaires about the child's listening ability were completed by a parent, a teacher, and the child.

Results: Structural equation models relating auditory processing abilities, cognitive abilities, listening ability and reading ability were developed. There was evidence that listening and reading abilities were associated with cognitive abilities when adjusting for auditory processing abilities, but little evidence that listening and reading abilities were associated with auditory processing abilities when adjusting for cognitive abilities.

Conclusions: It should not be assumed that auditory processing tests and cognitive tests measure separate abilities. When investigating the association between auditory processing abilities and real-world abilities, it is important to adjust for cognitive abilities. Children with listening difficulties should undergo cognitive assessments in addition to auditory processing assessments. 
49

50

51

52

In both audiological research and audiological practice, the topic of auditory processing continues to be of great interest. This interest is a result of the potential for auditory processing to explain listening difficulties that are worse than would be expected from a person's hearing threshold levels. There has been some interest in auditory processing in adults who may also have sensorineural hearing loss, but the main focus has been on children who have trouble listening at school despite having normal hearing thresholds.

A widely used definition of auditory processing, which we adopt as a working definition, is that of the American Speech-Language-Hearing Association (ASHA), which defines auditory processing as "the perceptual processing of auditory information in the CNS [central nervous system] and the neurobiologic activity that underlies that processing and gives rise to electrophysiologic auditory potentials" (ASHA 2005). Examples given by ASHA of tasks that depend on auditory processing skills include sound localisation, auditory pattern recognition, and listening in the presence of competing signals.

In the study of auditory processing an important role is played by cognitive abilities (primarily memory, attention and intelligence), but the distinction between auditory processing and cognitive abilities is not fully understood or agreed on. ASHA considers cognitive abilities to be "higher order" and excludes them as a cause of auditory processing disorder (ASHA 2005), whereas others have suggested that auditory processing disorder should be redefined as "primarily a cognitive disorder, rather than a sensory disorder" (Moore et al. 2010, p. e387). 
Another reason that auditory processing is of interest is the possibility that it affects the development of reading ability. Several studies have investigated this, with varying conclusions. Some studies have found evidence that auditory processing abilities may affect reading ability (for example, Tallal 1980; Downie et al. 2002; Walker et al. 2002; Beron \& Farkas 2004; Gyldenkærne et al. 2014), while others have found little evidence for such an effect (for example, Bretherton \& Holmes 2003; Plakas et al. 2013; Hakvoort et al. 2015). However, differences in methods across these studies make comparisons difficult.

Previous work with the data used here was described by Tomlin et al. (2015). The work described here extends the previous analysis in a few ways. Firstly, we make use of latent variables, which allow us to model abstract concepts and to separate a concept (for example, reading ability) from a measurement of the concept (for example, the score on a particular reading test). Secondly, instead of only testing hypotheses about individual model coefficients, we consider tests of groups of coefficients. Thirdly, we use a more sophisticated method for handling missing data.

The aim of this study was to investigate the associations between scores on behavioural tests commonly used as measures of auditory processing and cognition, and the relation of those scores to measures of listening ability and reading ability. More specifically, our aims were (1) to investigate the conventional distinction between auditory processing abilities and cognitive abilities, (2) to develop a plausible model relating auditory processing abilities, cognitive abilities, listening ability and reading ability, and (3) to investigate the association between each of listening and reading abilities and (a) auditory processing abilities, adjusting for cognitive abilities, and (b) cognitive abilities, adjusting for auditory processing abilities. 
Approval for this study was given by the Royal Victorian Eye and Ear Hospital Human Research Ethics Committee (10/941H) and the Victorian Department of Education (2010_000789). Informed consent was obtained for all children who participated.

\section{Subjects}

The subjects were 155 children aged between 7 and 13 years (median age 8.9 years; 89 boys and 66 girls). There were two separate recruitment streams, the first being children referred to the University of Melbourne Audiology Clinic for auditory processing assessment (105 children), and the second being children with no reported listening or academic concerns, recruited through their schools (50 children). All children in the study had hearing thresholds no worse than $15 \mathrm{~dB}$ HL at the octave frequencies from 0.25 to $8 \mathrm{kHz}$ in both ears, and tympanograms consistent with normal middle ear function in both ears (static admittance between 0.2 and $1.6 \mathrm{mmho}$ and peak pressure between -100 and $+20 \mathrm{daPa}$ ).

\section{Tests and measures}

\section{Auditory processing}

The auditory processing tests used were the dichotic digit test (DDT; Musiek 1983), the frequency pattern test (FPT; Musiek 1994), the gaps in noise test (GIN; Musiek et al. 2005), the masking level difference test (MLD; Wilson et al. 2003), and the Listening in Spatialized Noise - Sentences test (LISN-S; Cameron \& Dillon 2007). For DDT, GIN and MLD, the Auditec of St Louis compact disc recordings were used, and for FPT, the Department of Veterans Affairs compact disc recording was used. The ear order (for FPT and GIN) and test order were randomised. Stimuli were presented at $50 \mathrm{~dB}$ HL via TDH-39 headphones, except for LISN-S, which uses program-determined sound levels and Sennheiser headphones. 
123 The dichotic digit test, intended to assess dichotic listening, involved the child listening to sets of four numbers (numbers from 1 to 10, except for 7) consisting of two different numbers presented simultaneously, one to each ear, followed by another two different numbers presented simultaneously, one to each ear. The task was to repeat all four numbers in any order. After three trial sets, each child was tested on 20 sets of four numbers and received a percentage correct score for each ear based on the 40 numbers presented to that ear.

The frequency pattern test, intended to assess temporal sequencing, involved the child listening to sets of three tones, with each tone being either "low" $(880 \mathrm{~Hz})$ or "high" $(1122$ $\mathrm{Hz}$ ). The task was to state the pattern of lows and highs for each set in the correct order (for example, "low, high, low"), with each complete set being scored as either correct or incorrect. Left and right ears were tested separately, and after three trial sets each ear was tested on 15 sets and received a percentage correct score.

The gaps in noise test, intended to assess temporal resolution, involved the child listening to segments of broadband noise containing gaps of varying duration, and the task was to respond by pressing a button whenever a gap was detected. Left and right ears were tested separately. After a practice track, for the test track each ear received a score defined to be the shortest gap length in milliseconds to be reliably detected (at least 4 times out of 6), provided that longer gaps were also reliably detected.

The masking level difference test, intended to assess binaural interaction, involved the child listening for $500-\mathrm{Hz}$ tones in $500-\mathrm{Hz}$ narrowband noise under a homophasic condition (tones to the left and right ears in phase, and noise to the left and right ears in phase) and an 
antiphasic condition (noise in phase but tones $180^{\circ}$ out of phase). The antiphasic condition is usually found to be easier, and the score is the homophasic signal-to-noise ratio (SNR) threshold minus the antiphasic SNR threshold.

The Listening in Spatialized Noise - Sentences test, intended to assess the ability to understand speech in the presence of competing speech, involved the child listening to a series of sentences in the presence of other speech, with the task of repeating each sentence. In one condition, called "low-cue", the competing speech was spoken by the same voice and from the same direction as the target sentences, while in the other condition, called "highcue", the competing speech was spoken by a different voice and from different directions from the target sentences. For each of the two conditions, the score was the estimated SNR corresponding to $50 \%$ of words correct. The "spatial advantage" difference measure (Cameron \& Dillon 2007) is commonly used, but since the other auditory processing tests do not have commonly used derived measures, for consistency we did not use spatial advantage in this work.

\section{Cognitive}

Cognitive tests were chosen to assess working memory, sustained attention, and non-verbal intelligence.

Working memory was assessed using the digit span subtest of the Clinical Evaluation of Language Fundamentals, 4th edition (CELF-4; Semel et al. 2003). This involved sequences of digits of increasing length being presented to the child, with the child first having to repeat the digits in the same order as presented and then having to repeat the digits in reverse order. 
174 Sustained attention was assessed using the Integrated Visual and Auditory Continuous 175 Performance Test (IVA-CPT; Sandford \& Turner 1995). This was a computer-based test 176

The child received forward and reverse scaled scores depending on the number of sequences correctly repeated.

involving separate visual and auditory presentations of a sequence of 500 digits (after practice trials), each being either 1 or 2 , in random order, with the child having the task of responding whenever a 1 was presented. The auditory stimuli were set to comfortable listening levels and presented through Sennheiser headphones. The child received visual and auditory quotient scores.

Non-verbal intelligence was assessed using the Test of Nonverbal Intelligence, 4th edition (TONI-4; Brown et al. 2010). The test protocol was adhered to, which involved the child completing visually presented patterns of increasing complexity using a multiple-choice format. The child received a quotient score.

\section{Listening}

Listening ability was measured using a questionnaire completed by a parent, a questionnaire completed by the child's teacher, and a questionnaire completed by the child. The questionnaires are shown in Supplemental Digital Content 1.

The parent completed Fisher's Auditory Problems Checklist (Fisher 1976), which was made up of 25 yes/no items about the child's hearing and related things such as ear infections, attention, motivation and academic performance. 
The teacher completed a modified version of the questionnaire developed by Purdy et al.

197 (2002). The modified questionnaire contained seven items about the child's listening, concentration and general performance in different conditions, with each item rated by the teacher on a seven-point scale.

The child completed a shortened version of the questionnaire used by Purdy et al. (2009), which itself was a modified version of the LIFE-UK questionnaire (Canning n.d.). The child rated on a five-point scale how well he or she could hear in each of seven situations, mostly classroom situations.

We used item-total correlations to check the consistency of the items within each questionnaire. This led to the removal of six items from the parent questionnaire, one item from the child questionnaire, and no items from the teacher questionnaire. For more details about this, see Tomlin et al. (2015). The items that were removed are listed in Supplemental Digital Content 1. For each questionnaire, the overall score was the sum of the numericallycoded ratings for the items that were retained.

212

\section{Reading}

214 We used two measures of reading ability: the Wheldall Assessment of Reading Passages (WARP; Madelaine \& Wheldall 2002) and the National Assessment Program - Literacy and Numeracy (NAPLAN) reading score (Australian Curriculum, Assessment and Reporting Authority n.d.).

WARP involved the child reading a short story passage aloud for one minute and receiving a score indicating the number of words read correctly per minute. 
222 NAPLAN is an assessment for all children in Australia in Years 3, 5, 7 or 9 of school. It has scores for several areas but in this work we only used the reading score. The reading test involved the child reading material to himself or herself and answering questions (mostly multiple choice) about the material. We used the child's NAPLAN score if the NAPLAN test date was within 12 months of the child's assessment for this study.

\section{Statistical methods}

229

To remove the effects of age from the auditory processing, cognitive and reading scores, we expressed those scores as "z-scores", defined as the number of age-specific normative standard deviations from the age-specific normative mean. The directions of the z-scores were chosen so that higher z-scores indicate better performance. The CELF-4, IVA-CPT and TONI-4 already had scaled or quotient scores with known normative mean and standard deviation, so we obtained z-scores by simply rescaling those original scores. We used normative data to calculate z-scores for DDT (Tomlin et al. 2014), FPT (Tomlin et al. 2014), LISN-S (Cameron \& Dillon 2007) and WARP (Wheldall, Reference Note 1). For NAPLAN Reading, we calculated z-scores using data for the state of Victoria in the relevant year (Australian Curriculum, Assessment and Reporting Authority 2009-2012). For GIN and MLD, we calculated z-scores based on the data of the 50 children who had no reported listening problems. All further calculations and statistical analysis used these z-scores.

The main statistical method we used was structural equation modelling, which is a generalisation of multiple linear regression. Whereas linear regression models have one dependent variable and one or more explanatory variables, structural equation models can have more than one dependent variable and variables that act as both dependent and 
explanatory variables. Structural equation models can also include latent variables, which

247

248 represent abstract concepts that are not observed directly but only observed indirectly through other variables called their indicators. By including more than one indicator of a latent variable, a model can accommodate the idea that none of the indicators measures the underlying concept perfectly. A structural equation model consists of a set of equations involving several parameters, and fitting the model to a set of data involves determining the parameter values that make the model's predicted covariances between the observed variables match the sample covariances as closely as possible. The primary way of assessing the fit of a structural equation model is the model chi-squared test, with a statistically significant p-value indicating that the model is rejected (that is, that the model is incompatible with the data). We used a significance level of 0.05 .

Structural equation models were fitted in R (version 3.3.1; R Core Team 2016) using the lavaan package (version 0.5.22; Rosseel 2012). Models were fitted using the so-called MLR approach, which involves full-information maximum likelihood estimation (Arbuckle 1996) with standard errors and a model test statistic that are robust to non-normality (Rosseel 2017). This approach handles missing data without dropping subjects who have incomplete data and without imputing missing values.

Results

Some variables had missing data. The amount of missing data ranged from none for DDT, FPT, LISN-S and digit span, to 57\% for NAPLAN Reading (see Table 1). The reason for the large amount of missing data for NAPLAN Reading was that many parents no longer had the results. Descriptive statistics are given in Supplemental Digital Content 2. 


\section{Auditory processing vs cognitive}

272 For the question of classification of abilities as auditory processing abilities or cognitive abilities, we began by inspecting the Pearson correlations between the scores. These are shown in Table 2. We do not consider significance tests for these correlations to be important, but for readers who are interested, p-values are given in Supplemental Digital

\section{Content 3.}

The DDT, FPT and LISN-S scores were each more highly correlated with at least one score generally thought to be cognitive in nature (memory, attention, intelligence) than with the scores from all the other auditory processing tests. In some cases, an auditory processing score was even more highly correlated with a cognitive score than with the other score from the same test (for example, left DDT was more highly correlated with forward digit span than with right DDT). While these differences in correlations were not always statistically significant, this observation casts doubt on the assumption that the auditory processing tests measure some common "auditory processing" ability and the cognitive tests measure a separate "cognitive" ability.

We reach a similar conclusion if we consider average correlations instead of just the highest correlation. The DDT, FPT and LISN-S scores were each more highly correlated on average with the cognitive scores than with the scores from the other auditory processing tests (for example, left DDT was more highly correlated on average with the cognitive scores than with the seven scores from FPT, GIN, MLD and LISN-S). The GIN scores were more highly correlated on average with the scores from the other auditory processing tests than with the cognitive scores, but their average correlations with the other auditory processing scores were 
low (about 0.1). The MLD score had low correlations with all the other scores. This preliminary examination therefore provided very little evidence to support the conventional classification of scores as auditory processing scores versus cognitive scores.

To investigate this question using structural equation modelling, we fitted the model shown in Figure 1, with the variables classified as auditory processing or cognitive based on what the tests are commonly believed to measure. Following the usual convention, rectangles represent observed variables and ovals and circles represent latent variables. The unlabelled latent variables (circles) are error components. For example, the circle linked to DS-Fwd represents influences on the DS-Fwd score other than cognitive ability, including, but not limited to, random measurement error. Single-headed arrows (often called "paths") mean that the variable at the tail of the arrow is assumed to affect the variable at the head of the arrow. Double-headed arrows represent covariances that are not explained by other variables in the model.

Models like the one in Figure 1, containing latent variables and indicators but no singleheaded arrows from one latent variable to another, are called confirmatory factor analysis models, and are concerned with measurement of latent variables. In the simple model in Figure 1, the cognitive test scores depend on a common cognitive ability latent variable plus unknown factors unique to each test score (error components), and similarly for the auditory processing test scores. The model includes covariances between the error components of scores coming from the same test to account for the similarity of the tasks involved.

The model in Figure 1 was not rejected at the 5\% significance level $\left(\chi_{70}^{2}=88.0, p=0.07\right)$. However, the estimated correlation between the cognitive and auditory processing latent 
variables was close to 1 , indicating that in this simple model, the test score covariances are best explained if cognitive ability and auditory processing ability are essentially the same thing.

If we modify the model in Figure 1 by adding a constraint that the cognitive ability and auditory processing ability latent variables are uncorrelated, then the modified model is rejected $\left(\chi_{71}^{2}=176.7, p<0.001\right)$. This occurs because it has no ability to allow for the observed correlations between auditory processing test scores and cognitive test scores.

The data therefore provides evidence against the simple view that the cognitive tests measure an underlying cognitive ability and the auditory processing tests measure an underlying auditory processing ability that is unrelated to the cognitive ability. However, to keep the terminology simple, we will continue to use the term "cognitive tests" to refer to tests commonly thought of as cognitive tests (DS, CPT and TONI in this study) and "auditory processing tests" to refer to tests commonly thought of as auditory processing tests (DDT, FPT, GIN, MLD and LISN-S in this study). Similarly, we use "cognitive scores" and "auditory processing scores" to mean the scores from the cognitive and auditory processing tests, respectively, and "cognitive test skills" and "auditory processing test skills" to mean the skills that are tested by those tests.

We might next ask whether the cognitive scores and the auditory processing scores can be viewed as all measuring one underlying ability, which could be thought of as central nervous system development, a concept that has been suggested by Moore et al. (2013). To investigate this, we fitted a confirmatory factor analysis model with a single latent variable influencing the cognitive and auditory processing scores (with error covariances as in the 
previous model $)$, and this model was not rejected $\left(\chi_{71}^{2}=88.4, p=0.08\right)$. However, the usefulness of this model is questionable because the latent variable explained only a low proportion of variance of the indicators, with an average proportion of variance explained of only 0.21 . The possibility that the low proportion of variance explained was due to measurement error in the scores can be ruled out for at least some of the tests (FPT and GIN) because of a high correlation between left- and right-ear scores (see Table 2).

\section{Overall model}

We developed an overall structural equation model that included the cognitive scores, auditory processing scores, listening questionnaire scores, and reading scores. A diagram of the model is shown in Figure 2, with the meanings of the symbols being the same as described previously. The latent variables ddt, fpt, gin and lisn can be thought of as the underlying abilities tested by the dichotic digit test, frequency pattern test, gaps in noise test and LISN-S, respectively. In this model, the cognitive latent variables (memory, attention and intelligence) are assumed to directly affect the other latent variables. The auditory processing latent variables (ddt, fpt, gin and lisn) are assumed to affect listening ability directly, but they are assumed to affect reading ability only indirectly through listening ability.

The masking level difference score was omitted from the model because its correlations with the other variables were low. The visual attention score and child's questionnaire score were omitted because including them (as additional indicators of attention and listening ability, respectively) caused poor fit or problems with the fitted model.

Error covariances between pairs of left-ear scores were included because of a common reliance on the left ear, and similarly for pairs of right-ear scores (these are the double-headed 
arrows at the left edge of Figure 2). The error covariance between WARP score and teacher questionnaire score had less theoretical justification and was included to improve the fit of the model. The interpretation of that error covariance, if it is positive, is that children who tended to score better on WARP for reasons other than reading ability also tended to be rated as better listeners by their teachers for reasons other than listening ability.

As a technical aside, note that in Figure 2, the attention and intelligence latent variables each have only one indicator, which means that their indicators' error variances must be assumed instead of being estimated. We assumed error variances of zero, which was equivalent to simply omitting those two latent variables and replacing each one by its indicator.

The test of model fit had test statistic $\chi_{73}^{2}=81.8$ with a corresponding p-value of 0.22 , so the model was not rejected at the $5 \%$ significance level. In addition to the model chi-squared test, the fit of a structural equation model is commonly assessed using other measures called "fit indices". We used the standardised root mean square residual (SRMR) (Kline 2011) and "robust" versions of the root mean squared error of approximation (RMSEA) (BrosseauLiard et al. 2012), the Comparative Fit Index (CFI) and the Tucker-Lewis Index (TLI) (Brosseau-Liard \& Savalei 2014). This model had SRMR $=0.05, \mathrm{RMSEA}=0.03, \mathrm{CFI}=$ 0.99, and TLI $=0.98$, all of which are indicative of good fit (Hu \& Bentler 1999).

Table 3 contains estimates of the model's standardised parameters and, where applicable, the p-value for each test of the null hypothesis that the standardised parameter is zero. "Standardised" means that the parameter estimates are based on the variables being scaled to have a variance of 1 , so that the factor loadings (coefficients of paths from latent variable to 
indicator) can be interpreted as correlations between the latent variable and the indicator, and covariances (represented by double-headed curved arrows) are correlations.

The main paths of interest are those representing an effect of one latent variable on another, especially the effects on listening ability and on reading ability. For each of the seven predictor variables of listening ability in the model (memory, attention, intelligence, ddt, fpt, gin, lisn), the null hypothesis of a coefficient value of zero could not be rejected. The interpretation is that for listening ability, we cannot confidently conclude that any of those seven variables has explanatory value beyond what can be explained by the other six. It should however be noted that correlations among the predictor variables cause the statistical power of these tests to be reduced.

For reading ability, the null coefficient value of zero was rejected for memory, attention and intelligence, but not for listening ability. The estimated effects on reading ability were in the expected direction, with better memory, better attention and higher intelligence being associated with better reading ability. The estimated association with reading ability was strongest for memory, with a coefficient estimate of 0.56 (an increase in memory by one standard deviation was associated with an estimated increase in reading ability by 0.56 standard deviations if attention, intelligence and listening ability are constant).

Subjects with extreme values had the potential to be overly influential on the fitting of the model. To check this, we re-fitted the model leaving out, in turn, (1) two subjects with very poor right DDT scores, (2) one subject with a very poor LISN-S high-cue score, and (3) one subject with a very poor LISN-S low-cue score. These three fitted models were similar to the model fitted on the full data set. 
We note that the six covariances between the DDT, FPT and GIN error terms were included in the model based on theoretical considerations, but from a statistical point of view they were not required. When they were left out, the resulting model was still not rejected $\left(\chi_{79}^{2}=\right.$ 93.7; $p=0.12$ ) and there were no major changes to the parameter estimates and $p$-values.

To test the combined influence of the auditory processing test skills, or the combined influence of the cognitive test skills, we can test a null hypothesis that the coefficients of several paths are all zero. This could be done using the overall model, but the interpretation would be difficult because in that model the auditory processing test skills depend on the cognitive test skills, and reading ability depends on listening ability.

To allow these combined effects to be tested in a way that can be interpreted more clearly, we considered separate simpler models for each of listening ability and reading ability. The model for reading ability is shown in Figure 3, with the model for listening ability being the same except that in place of the reading ability latent variable and its two indicators, there is a listening ability latent variable with two indicators (parent questionnaire score and teacher questionnaire score). The model for listening ability is shown in Supplemental Digital Content 4 . The fit of these models was not ideal, with a small number of negative variance estimates, but they still allow the hypotheses of interest to be tested.

To test the combined effect of the auditory processing test skills, we test the null hypothesis that the coefficients of the paths from ddt, fpt, gin and lisn to listening or reading ability are all zero, and to test the combined effect of the cognitive test skills, we test the null hypothesis 
that the coefficients of the paths from memory, attention and non-verbal intelligence to listening or reading ability are all zero.

446

447 The test statistics and p-values for these tests are shown in Table 4. For both listening and reading, the null hypothesis of no effect of the auditory processing test skills was not rejected, and the null hypothesis of no effect of the cognitive test skills was rejected. If we leave the error covariances between left-ear scores and between right-ear scores out of the models, we reach the same conclusions.

452

\section{Discussion}

One of the main results of this study was a lack of evidence of association between the skills tested by the auditory processing tests and each of listening and reading abilities when adjusting for the cognitive test skills, together with clear evidence of association between the cognitive test skills and each of listening and reading when adjusting for the auditory processing test skills (Table 4). The statistical significance of the associations with the cognitive test skills suggests that the lack of statistical significance for the auditory processing test skills was not due to inadequate statistical power.

This result was consistent with some previous studies and inconsistent with other previous studies. It was consistent with Moore et al. (2010), who found that much more variance in questionnaire results was explained by cognitive ability and their measure of attention than by auditory processing scores. It was also consistent with Plakas et al. (2013) and Hakvoort et al. (2015), who concluded that their electrophysiological measures of auditory processing ability were associated with reading ability only through a common association with genetic factors. 
470 Our result was seemingly inconsistent with some previous studies. Anderson et al. (2013)

471 found an association between central processing and speech understanding in noise, but their

472 study was quite different from ours because they used speech-in-noise tests instead of

473 questionnaires and their subjects were adults, some of whom had hearing loss. Several studies

474 (Tallal 1980; Downie et al. 2002; Walker et al. 2002; Beron \& Farkas 2004; Gyldenkærne et

al. 2014) have found associations between measures of auditory processing ability and measures of reading ability, but while some of these studies adjusted for one or more cognitive variables, none of them adjusted for all three of memory, attention and intelligence. We cannot confidently say that had they adjusted for all three of these, they would not have found an association between auditory processing and reading, but it is a possible explanation for the apparent inconsistency. Another contributing factor may have been adjusting for the wrong "type" of cognitive variable - for example, Beron and Farkas (2004) adjusted for longterm retrieval memory when working memory may have been more relevant.

The lack of evidence of association between auditory processing test skills and each of listening and reading when adjusting for cognitive test skills has the interpretation that it is possible that if a child's memory, attention and intelligence levels are known, then the child's auditory processing scores give no additional information about the child's listening and reading abilities. It seems unlikely that auditory processing scores would have absolutely no association with listening and reading beyond a common reliance on cognitive abilities, but it is plausible that after adjusting for cognitive abilities, the auditory processing scores are associated with listening and reading only very weakly. If that were the case, it would mean that researchers and clinicians who focus on auditory processing scores for a presumed association with listening or reading ability would be focusing on the "wrong" variables. One 
practical consequence of this might be that when a child presents to a clinic with reported listening difficulties, the training recommended to remediate the listening difficulties targets the wrong skills. We note that it is possible that the cognitive variables we measured in this study are not the "right" variables either, since there could be important variables that we omitted.

The implication for future research is that research studying associations between auditory processing scores and any measure of real-world ability (for example, reading ability) should measure memory, attention and intelligence, and adjust for them when looking at the association between auditory processing and the real-world ability. Not doing so risks finding a spurious association due to correlations with omitted variables. This can be illustrated with our data. For the simple reading model in Figure 3, if we leave out the memory latent variable and its indicators, then the p-value for the test of the combined effect of the auditory processing variables decreases from 0.72 to 0.002 . Finding a spurious association may not necessarily be worthless, but it would mean that we would not have the full picture, and it could lead to a suboptimal choice of tests for clinical use.

The implication for clinical practice is that when a child presents to a clinic because of concerns about listening difficulties (for example, difficulty with listening in the classroom), the child's memory, attention and intelligence should be assessed directly. We still recommend the use of auditory processing testing, but our results suggest that in populations like the one studied here, it may be less important than cognitive testing. It should be noted, however, that the relative importance of auditory processing and cognitive testing may be different in different populations. We note, for example, that among the clinical subjects in this study, the proportion who met the criteria for spatial processing disorder (as described by 
519 Cameron \& Dillon 2008) was only 3\%, but among 666 children assessed in a network of 520 clinics across Australia, the proportion was 20\% (Cameron et al. 2015). This large difference

521

522

523

524

525

526

527

528

529

530

531

532

533

534

535

536

537

538

539

540

541

542 The very low correlations between the MLD score and the other measures in Table 2 are in proportions indicates that children were arriving at the different clinics with a different mix of problems behind their reported listening difficulties. It is not surprising that if in a particular group, cognitive deficits are more common, then the importance of auditory processing abilities in explaining their listening difficulties will be reduced. The results of this study are therefore unlikely to generalise to all clinical populations.

The correlations and confirmatory factor analysis models have the interpretation that we should not assume that auditory processing tests measure a common "auditory processing" ability while cognitive tests measure a separate "cognitive" ability. This suggests that an overall diagnosis of "auditory processing disorder" may not be useful in guiding treatment. Rather, diagnoses centred on deficits in specific abilities, whether those abilities be thought of as cognitive or auditory processing in nature, seem more justified. The practice of diagnosing an unspecified type of auditory processing disorder using a criterion such as attaining scores at least two standard deviations below the mean on at least two auditory processing tests can also be criticised for being based primarily on statistical considerations rather than on real-world consequences of deficiencies in the skills being tested (Dillon et al. 2012). None of this takes away from the usefulness of the term "auditory processing disorder" as an umbrella term for various deficits in "the perceptual processing of auditory information in the CNS" (ASHA 2005) as long as we do not assume that all people with such a deficit have exactly the same type of deficit or need the same treatment. worth commenting on. Since the MLD task just involves detecting a tone in noise, its 
cognitive demands are less than for more complex auditory tasks, so low correlations with the memory, attention and intelligence scores are not surprising. Of the other auditory processing scores, we would expect MLD to be most strongly related to DDT and LISN-S because they also involve binaural processing, while FPT and GIN do not. However, previous research has shown that it is common for there to be a marked deficit in one type of binaural processing (identification of a frontal target in the presence of spatially separated maskers) despite performance on other binaural processing tasks (dichotic perception and MLD) being normal (Cameron \& Dillon 2008). This can be explained by noting that although all types of binaural processing rely on some combination of interaural level differences and interaural time differences, the way those cues are used is different for different tasks. We might also expect a low correlation between MLD score and real-life listening ability, because the complete phase reversal in the antiphasic condition cannot occur in real life, unless the signal is a pure tone. Even then, for any given direction of arrival, phase reversal will only occur if the frequency of the pure tone is one of a small number of specific frequencies. It is therefore possible that the ability tested by MLD is not useful in real life.

It seems reasonable to think that auditory processing abilities may exist independently of cognitive abilities (memory, attention and intelligence), and that it is only the auditory processing test scores (not the underlying auditory abilities) that are affected by cognitive abilities. In that case, if a more "pure" measure of a specific type of auditory processing ability is desired then difference measures (or ratio measures) of the type used by Cameron and Dillon (2007) and Moore et al. (2010) are likely to be better than raw measures. Because different parts of the same test could have different levels of dependence on cognitive abilities, we should not necessarily assume that difference measures remove the cognitive component completely, but the effect of cognitive abilities should at least be reduced. 
570 Self-report measures (for example, questionnaires) are commonly used in research and in

571 clinical work, but we should be cautious when interpreting such measures. We should not

572 necessarily assume that self-report scores exclusively, or even primarily, reflect the things

573 they are intended to measure. In our overall structural equation model (Figure 2), if we

574 reverse the arrow between listening ability and reading ability then the model is still not

575 rejected. Ratings of a child's listening ability could be affected by what the respondent knows

576 about the child's ability in other areas, which could result in misleading conclusions. For

577 example, if a questionnaire on listening is affected by the respondent's knowledge of the

578 child's academic ability then we would overestimate the strength of association between

579 listening ability and academic ability. In our overall model, the covariance between the error

580 components of the WARP score and the teacher questionnaire score could be explained by

581 the teacher rating being influenced by knowledge of other aspects of the child that also

582 correlate with the WARP score.

583

584 When interpreting structural equation models, it is important to note that a non-significant model chi-squared test does not "confirm" the model; it only means that the model cannot be rejected. There may be other models that fit the data as well as or better than the one being considered. It is also important to note that modifying a model on the basis of statistical criteria, as opposed to subject knowledge, can cause the evaluation of model fit (chi-squared test and fit indices) to be over-optimistic. We therefore tried to use theoretical knowledge and reasoning, rather than statistical criteria, as much as possible when specifying the models, but the inclusion of the WARP-Teacher error covariance was influenced by statistical criteria, as was the exclusion of the visual attention score and the child questionnaire score. Our 
modelling should therefore be viewed as having included an exploratory element, and the models should ideally be verified on a new set of data.

A limitation of this study was the sample size. While a sample size of 155 would be considered large in some contexts, it is quite small for fitting a structural equation model of the complexity of our overall model, and the effective sample size was even smaller because of the missing data. Had we had a larger sample size, we would have considered additional models that were more detailed.

Another limitation was the use of Fisher's Auditory Problems Checklist as a measure of the child's listening ability. We used this questionnaire because it is relatively commonly used in practice, but some of its items did not directly relate to "listening ability", and were instead about other things like attention and motivation.

A further limitation that we have not examined (due to the sample size) was that the children were sampled from two distinct populations: one comprising children who were referred for an auditory processing assessment, and the other comprising children with no known listening or learning difficulties. It is possible that the two populations are different in abilities not measured in this study and that those unknown differences influenced the associations of interest.

\section{Acknowledgements}

We thank the children, parents and teachers who participated in this study. We thank Dr Julia Sarant for supervision of the TONI-4 and CELF-4 test administration, and Dr Mridula Sharma for a helpful discussion. Funding for this project was provided by the HEARing 
618 Cooperative Research Centre, an Australian Government initiative. Dr Dillon acknowledges

619

620

621

622

623

624

625

626

627

628

629

630

631

632

633

634

635

636

637

638

639

640

641 the support of Macquarie University and the NIHR Manchester Biomedical Research Centre.

We thank the reviewers and the Section Editor for their helpful comments.

D.T. designed and ran the study, and prepared the data for analysis in consultation with H.D.

M.S. performed the data analysis, which had been planned by H.D. and M.S. M.S. wrote the paper with contributions and feedback from H.D. and D.T.

The authors have no conflicts of interest to disclose.

\section{References}

American Speech-Language-Hearing Association. (2005). (Central) auditory processing disorders. Retrieved from https://www.asha.org/policy/TR2005-00043/

Anderson, S., White-Schwoch, T., Parbery-Clark, A., et al. (2013). A dynamic auditorycognitive system supports speech-in-noise perception in older adults. Hear Res, 300, 18-32. Arbuckle, J. L. (1996). Full information estimation in the presence of incomplete data. In G. A. Marcoulides \& R. E. Schumacker (Eds.), Advanced Structural Equation Modeling: Issues and Techniques (pp. 243-277). Mahwah, NJ: Lawrence Erlbaum Associates.

Australian Curriculum, Assessment and Reporting Authority. (n.d.). NAPLAN: Reading.

Retrieved from https://www.nap.edu.au/naplan/reading

Australian Curriculum, Assessment and Reporting Authority. (2009-2012). NAPLAN

national reports. Retrieved from https://www.nap.edu.au/results-and-reports/national-reports

Beron, K. J., \& Farkas, G. (2004). Oral language and reading success: A structural equation modeling approach. Struct Equ Modeling, 11, 110-131. 
642 Bretherton, L., \& Holmes, V. M. (2003). The relationship between auditory temporal 643 processing, phonemic awareness, and reading disability. J Exp Child Psychol, 84, 218-243.

644 Brosseau-Liard, P. E., \& Savalei, V. (2014). Adjusting incremental fit indices for 645 nonnormality. Multivariate Behav Res, 49, 460-470.

646 Brosseau-Liard, P. E., Savalei, V., Li, L. (2012). An investigation of the sample performance 647 of two nonnormality corrections for RMSEA. Multivariate Behav Res, 47, 904-930.

648 Brown, L., Sherbenou, R. J., Johnsen, S. K. (2010). Test of Nonverbal Intelligence (4th ed.). 649 Austin, TX: Pro-Ed.

650 Cameron, S., \& Dillon, H. (2007). Development of the Listening in Spatialized Noise 651 Sentences test (LISN-S). Ear Hear, 28, 196-211.

652 Cameron, S., \& Dillon, H. (2008). The Listening in Spatialized Noise - Sentences test 653 (LISN-S): Comparison to the prototype LISN and results from children with either a suspected (central) auditory processing disorder or a confirmed language disorder. J Am Acad 655 Audiol, 19, 377-391.

Cameron, S., Glyde, H., Dillon, H., et al. (2015). Results from a national central auditory processing disorder service: A real-world assessment of diagnostic practices and remediation 658 for central auditory processing disorder. Semin Hear, 36, 216-236. Hearing Profile). Retrieved from http://soundingboard.earfoundation.org.uk/downloads/life-uk_ihp.pdf Dillon, H., Cameron, S. Glyde, H., et al. (2012). An opinion on the assessment of people who may have an auditory processing disorder. J Am Acad Audiol, 23, 97-105. deficits in children with periventricular brain injury. Brain Lang, 80, 208-225. Fisher, L. I. (1976). Fisher's Auditory Problems Checklist. Bemidji, MN: Life Products. 
667

668

669

670

671

672

673

674

675

676

677

678

679

680

681

682

683

684

685

686

687

688

689

Gyldenkærne, P., Dillon, H., Sharma, M., et al. (2014). Attend to this: The relationship between auditory processing disorders and attention deficits. J Am Acad Audiol, 25, 676-687. Hakvoort, B., van der Leij, A., Maurits, N., et al. (2015). Basic auditory processing is related to familial risk, not to reading fluency: An ERP study. Cortex, 63, 90-103.

Hu, L.-t., \& Bentler, P. M. (1999). Cutoff criteria for fit indexes in covariance structure analysis: Conventional criteria versus new alternatives. Struct Equ Modeling, 6, 1-55. Kline, R. B. (2011). Principles and Practice of Structural Equation Modeling (3rd ed.). New York, NY: The Guilford Press.

Madelaine, A., \& Wheldall, K. (2002). Further progress towards a standardised curriculumbased measure of reading: calibrating a new passage reading test against the New South Wales Basic Skills Test. Educ Psychol, 22, 461-471.

Moore, D. R., Ferguson, M. A., Edmondson-Jones, M., et al. (2010). Nature of auditory processing disorder in children. Pediatrics, 126, e382-e390.

Moore, D. R., Rosen, S., Bamiou, D.-E., et al. (2013). Evolving concepts of developmental auditory processing disorder (APD): A British Society of Audiology APD Special Interest Group ‘white paper'. Int J Audiol, 52, 3-13.

Musiek, F. E. (1983). Assessment of central auditory dysfunction: the dichotic digit test revisited. Ear Hear, 4, 79-83.

Musiek, F. E. (1994). Frequency (pitch) and duration pattern tests. J Am Acad Audiol, 5, 265268.

Musiek, F. E., Shinn, J. B., Jirsa, R., et al. (2005). GIN (Gaps-In-Noise) test performance in subjects with confirmed central auditory nervous system involvement. Ear Hear, 26, 608618. 
690

691

692

693

694

695

696

697

698

699

700

701

702

703

704

705

706

707

708

709

710

711

712

713

714

Plakas, A., van Zuijen, T., van Leeuwen, T., et al. (2013). Impaired non-speech auditory processing at a pre-reading age is a risk-factor for dyslexia but not a predictor: An ERP study.

Cortex, 49, 1034-1045.

Purdy, S. C., Kelly, A. S., Davies, M. G. (2002). Auditory brainstem response, middle latency response, and late cortical evoked potentials in children with learning disabilities. $J$ Am Acad Audiol, 13, 367-382.

Purdy, S. C., Smart, J. L., Baily, M., et al. (2009). Do children with reading delay benefit from the use of personal FM systems in the classroom? Int J Audiol, 48, 843-852.

R Core Team. (2016). R: A language and environment for statistical computing. Available from https://www.r-project.org

Rosseel, Y. (2012). lavaan: An R package for structural equation modeling. J Stat Softw, 48, $1-36$.

Rosseel, Y. (2017). The lavaan tutorial. Retrieved from

http://lavaan.ugent.be/tutorial/tutorial.pdf

Sandford, J. A., \& Turner, A. (1995). Integrated Visual and Auditory Continuous

Performance Test. Richmond, VA: BrainTrain.

Semel, E., Wiig, E. H., Secord, W. A. (2003). Clinical Evaluation of Language

Fundamentals (4th ed.). San Antonio, TX: The Psychological Corporation.

Tallal, P. (1980). Auditory temporal perception, phonics, and reading disabilities in children.

Brain Lang, 9, 182-198.

Tomlin, D., Dillon, H., Kelly, A. S. (2014). Allowing for asymmetric distributions when comparing auditory processing test percentage scores with normative data. J Am Acad Audiol, $25,541-548$.

Tomlin, D., Dillon, H., Sharma, M., et al. (2015). The impact of auditory processing and cognitive abilities in children. Ear Hear, 36, 527-542. 
715 Walker, M. M., Shinn, J. B., Cranford, J. L., et al. (2002). Auditory temporal processing 716 performance of young adults with reading disorders. J Speech Lang Hear Res, 45, 598-605.

717 Wilson, R. H., Moncrieff, D. W., Townsend, E. A., et al. (2003). Development of a 500-Hz 718 masking-level difference protocol for clinic use. J Am Acad Audiol, 14, 1-8.

719

720

Reference notes

721

1. Wheldall, K. (1998). Unpublished data.

722

723

724

725

726

727

728

729

730

731

732

733

734

735

736

737

738 
Figure 1: Confirmatory factor analysis model. Rectangles represent observed variables, ovals and circles represent latent variables, single-headed arrows represent causal effects, and double-headed arrows represent covariances. Unlabelled latent variables (circles) are error components. Abbreviations are explained in Table 1.

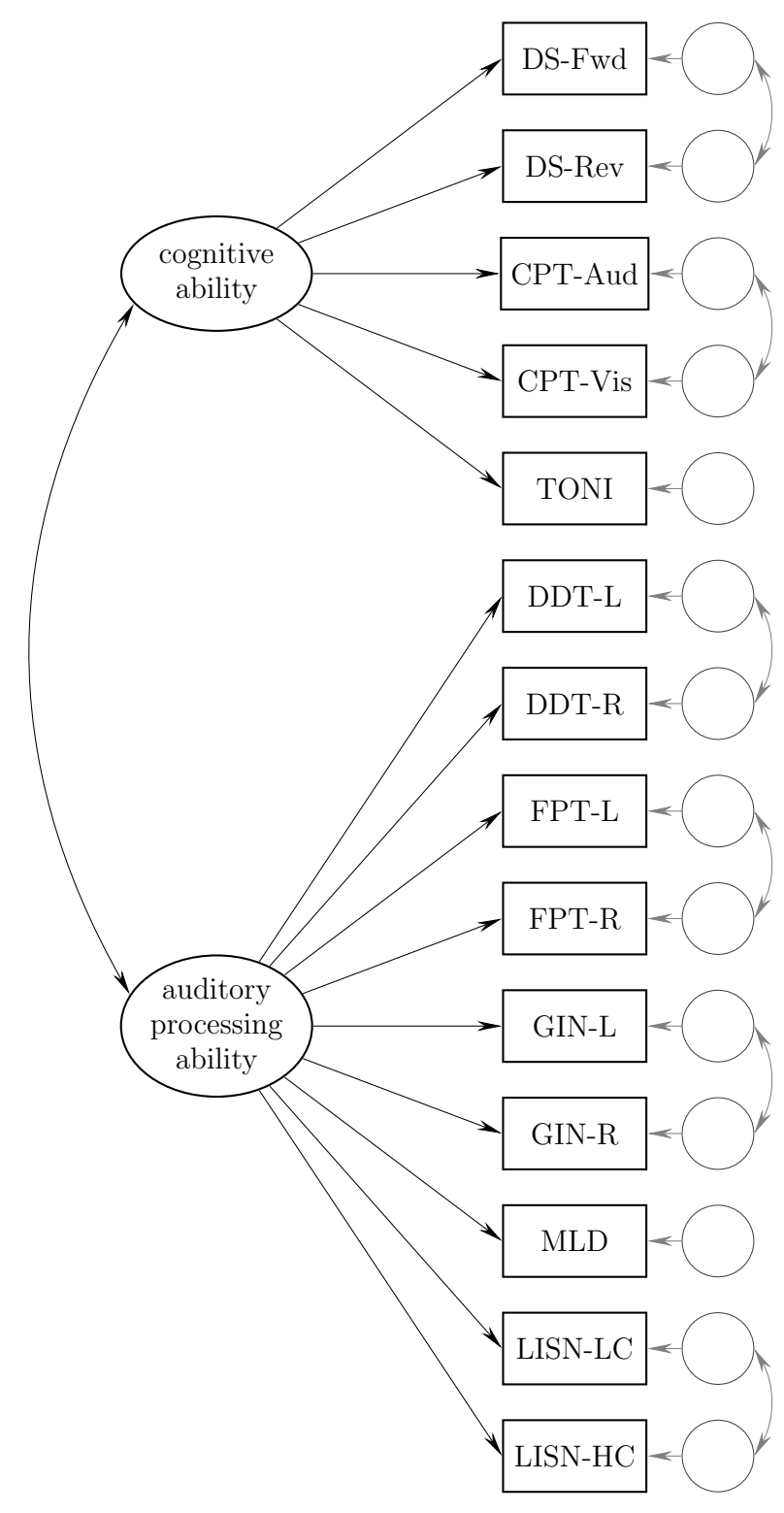


Figure 2: Overall model. Rectangles represent observed variables, ovals and circles represent latent variables, single-headed arrows represent causal effects, and double-headed arrows represent covariances. Unlabelled latent variables (circles) are error components. Abbreviations are explained in Table 1. The model includes covariances between each pair of the memory, attention and non-verbal intelligence latent variables, but to avoid cluttering, these covariances are not shown in the diagram.

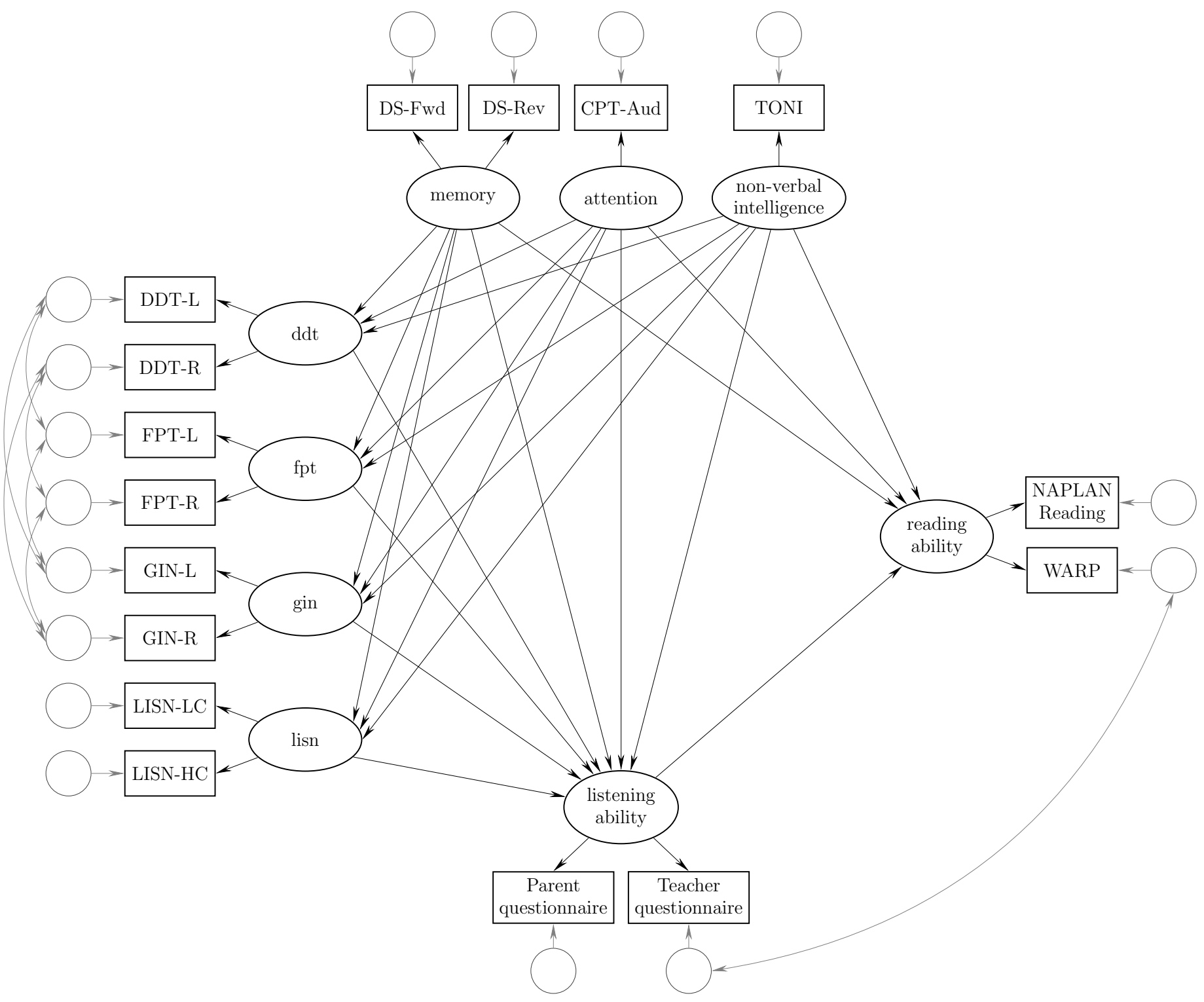


Figure 3: Simplified model for reading ability. Rectangles represent observed variables, ovals and circles represent latent variables, single-headed arrows represent causal effects, and double-headed arrows represent covariances. Unlabelled latent variables (circles) are error components. Abbreviations are explained in Table 1.

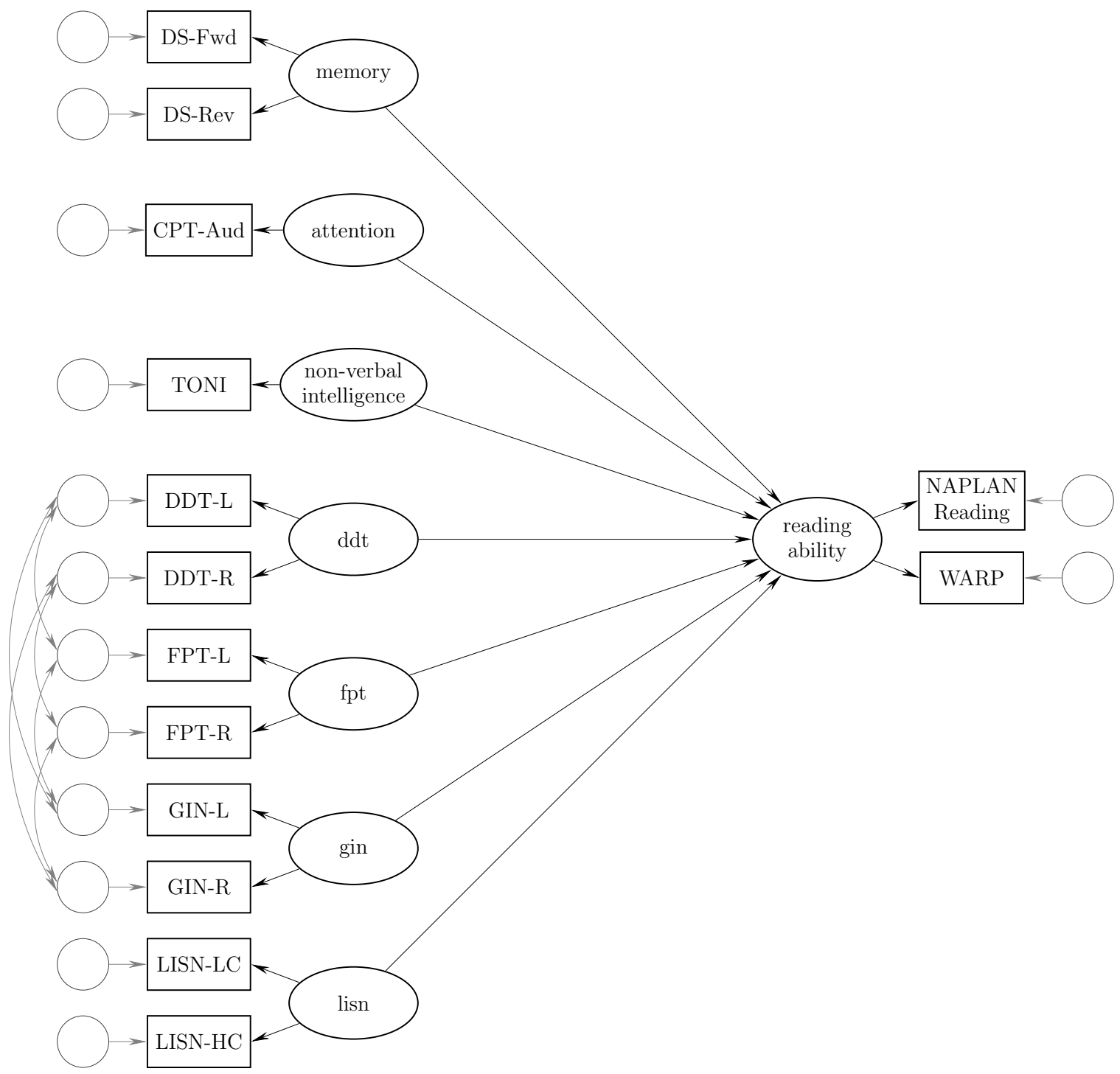


Table 1: Abbreviation and percentage of missing data for each measure.

\begin{tabular}{llc}
\hline Abbreviation & Meaning & Missing \% \\
\hline DDT-L & Dichotic digit test: Left ear & 0.0 \\
DDT-R & Dichotic digit test: Right ear & 0.0 \\
FPT-L & Frequency pattern test: Left ear & 0.0 \\
FPT-R & Frequency pattern test: Right ear & 0.0 \\
GIN-L & Gaps in noise test: Left ear & 1.3 \\
GIN-R & Gaps in noise test: Right ear & 1.3 \\
MLD & Masking level difference test & 3.9 \\
LISN-LC & Listening in Spatialized Noise - Sentences: Low-cue & 0.0 \\
LISN-HC & Listening in Spatialized Noise - Sentences: High-cue & 0.0 \\
DS-Fwd & Digit span test: Forward & 0.0 \\
DS-Rev & Digit span test: Reverse & 0.0 \\
CPT-Aud & Continuous Performance Test: Auditory & 17.4 \\
CPT-Vis & Continuous Performance Test: Visual & 23.2 \\
TONI & Test of Nonverbal Intelligence & 5.2 \\
Parent quest. & Parent questionnaire & 27.7 \\
Teacher quest. & Teacher questionnaire & 38.1 \\
Child quest. & Child questionnaire & 27.1 \\
WARP & Wheldall Assessment of Reading Passages & 17.4 \\
NAPLAN Reading & National Assessment Program - Literacy and Numeracy: Reading & 57.4 \\
\hline
\end{tabular}


Table 2: Pearson correlations of the auditory processing and cognitive z-scores (with pairwise deletion of missing data). For each pair of variables, a positive correlation indicates that in this sample, improved performance on one measure was associated with improved performance on the other measure. Abbreviations are explained in Table 1.

\begin{tabular}{|c|c|c|c|c|c|c|c|c|c|c|c|c|c|c|}
\hline & 宣 & $\begin{array}{l}\frac{a}{1} \\
\frac{1}{0}\end{array}$ & 宾 & $\begin{array}{l}\frac{\alpha}{1} \\
\frac{1}{\mid c} \\
\end{array}$ & 莣 & 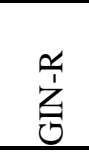 & $\stackrel{\ominus}{\stackrel{\rho}{2}}$ & 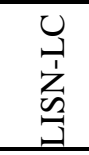 & 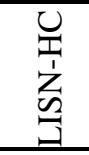 & $\begin{array}{l}\overrightarrow{3} \\
\dot{1} \\
\dot{\omega} \\
\omega^{\prime}\end{array}$ & $\begin{array}{l}\vec{\partial} \\
\frac{2}{1} \\
\tilde{n}^{\prime 2}\end{array}$ & 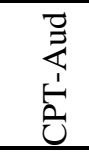 & $\begin{array}{l}\sum_{1}^{\infty} \\
\stackrel{0}{0}\end{array}$ & $\begin{array}{l}z \\
\\
\end{array}$ \\
\hline DDT-L & 1.00 & 0.38 & 0.33 & 0.27 & 0.04 & 0.08 & -0.07 & 0.24 & 0.18 & 0.43 & 0.39 & 0.18 & 0.28 & 0.38 \\
\hline DDT-R & 0.38 & 1.00 & 26 & 0.31 & 0.07 & 0.10 & -0.12 & 0.21 & 0.11 & 0.36 & 0.34 & 0.16 & 0.16 & 0.28 \\
\hline $\mathrm{F}$ & 0.33 & 0.26 & 0 & 0.91 & 0.18 & 0.15 & 0 & 0.13 & 0.08 & 6 & 0.38 & 0.17 & 0.11 & 0.43 \\
\hline FPT-R & 0.27 & 0.31 & 0.91 & 1.00 & 0.21 & 0.16 & -0.01 & 0.12 & 0.14 & 0.23 & 0.33 & 0.13 & 0.05 & 0.41 \\
\hline GIN-L & 0.04 & 0.07 & 0.18 & 0.21 & 1.00 & 0.80 & -0.02 & 0.05 & 0.16 & 0.08 & 0.05 & 0.11 & -0.04 & 0.12 \\
\hline GIN-R & 0.08 & & 15 & 0.16 & 0.80 & 1.00 & -0.05 & 0.02 & 0.08 & 0.09 & 0.03 & 0.07 & 0.01 & 0.14 \\
\hline MLD & -0.07 & -0.12 & 0.00 & -0.01 & -0.02 & -0.05 & 1.00 & -0.05 & -0.08 & 0.15 & -0.05 & -0.06 & -0.01 & 0.07 \\
\hline LISN-LC & 0.24 & 0.21 & 0.13 & 0.12 & 0.05 & 0.02 & -0.05 & 1.00 & 0.24 & 0.27 & 0.18 & 0.04 & 0.00 & 0.28 \\
\hline LISN-HC & 0.18 & 0. & 0.08 & 0.14 & 0.16 & 0.08 & -0.08 & 0.24 & 1.00 & 0 . & 0.11 & 0.20 & 0.02 & 0.22 \\
\hline DS-Fwd & 0.43 & 0.36 & 0.26 & 0.23 & 0.08 & 0.09 & 0.15 & 0.27 & 0.12 & 1.00 & 0.47 & 0.16 & 0.12 & 0.31 \\
\hline DS-Rev & 0.39 & 0.34 & 0.38 & 0.33 & 0.05 & 0.03 & -0.05 & 0.18 & 0.11 & 0.47 & 1.00 & 0.39 & 0.29 & 0.32 \\
\hline CPT-Aud & 0.18 & 0.16 & 0.17 & 0.13 & 0.11 & 0.07 & -0.06 & 0.04 & 0.20 & 0.16 & 0.39 & 1.00 & 0.65 & 0.21 \\
\hline CPT-Vis & 0.28 & 0.16 & 0.11 & 0.05 & -0.04 & 0.01 & -0.01 & 0.00 & 0.02 & 0.12 & 0.29 & 0.65 & 1.00 & 0.22 \\
\hline TONI & 0.38 & 0.28 & 0.43 & 0.41 & 0.12 & 0.14 & 0.07 & 0.28 & 0.22 & 0.31 & 0.32 & 0.21 & 0.22 & 1.00 \\
\hline
\end{tabular}


Table 3: Estimates of standardised parameters of the overall model (Figure 2) and, where applicable, $\mathrm{p}$-values for the tests that each standardised parameter is zero. Parentheses around a variable name indicate the error component of that variable. Abbreviations are explained in Table 1.

\begin{tabular}{|c|c|c|c|c|c|}
\hline Parameter & Estimate & p-value & Parameter & Estimate & p-value \\
\hline memory $\rightarrow$ DS-Fwd & 0.66 & $<0.001$ & memory $\rightarrow$ ddt & 0.88 & $<0.001$ \\
\hline memory $\rightarrow$ DS-Rev & 0.70 & $<0.001$ & attention $\rightarrow$ ddt & -0.08 & 0.52 \\
\hline attention $\rightarrow$ CPT-Aud & 1.00 & & intelligence $\rightarrow \mathrm{ddt}$ & 0.13 & 0.26 \\
\hline intelligence $\rightarrow$ TONI & 1.00 & & memory $\rightarrow \mathrm{fpt}$ & 0.37 & 0.002 \\
\hline $\mathrm{ddt} \rightarrow \mathrm{DDT}-\mathrm{L}$ & 0.67 & $<0.001$ & attention $\rightarrow \mathrm{fpt}$ & -0.07 & 0.52 \\
\hline $\mathrm{ddt} \rightarrow \mathrm{DDT}-\mathrm{R}$ & 0.58 & $<0.001$ & intelligence $\rightarrow \mathrm{fpt}$ & 0.28 & 0.004 \\
\hline $\mathrm{fpt} \rightarrow$ FPT-L & 0.98 & $<0.001$ & memory $\rightarrow$ gin & 0.09 & 0.48 \\
\hline $\mathrm{fpt} \rightarrow$ FPT-R & 0.92 & $<0.001$ & attention $\rightarrow$ gin & 0.12 & 0.17 \\
\hline gin $\rightarrow$ GIN-L & 0.97 & $<0.001$ & intelligence $\rightarrow$ gin & 0.06 & 0.71 \\
\hline gin $\rightarrow$ GIN-R & 0.82 & $<0.001$ & memory $\rightarrow$ lisn & 0.38 & 0.07 \\
\hline lisn $\rightarrow$ LISN-LC & 0.53 & $<0.001$ & attention $\rightarrow$ lisn & 0.03 & 0.90 \\
\hline lisn $\rightarrow$ LISN-HC & 0.44 & $<0.001$ & intelligence $\rightarrow$ lisn & 0.35 & 0.02 \\
\hline listening $\rightarrow$ Parent quest. & 0.92 & $<0.001$ & memory $\rightarrow$ listening & -0.04 & 0.97 \\
\hline listening $\rightarrow$ Teacher quest. & 0.72 & $<0.001$ & attention $\rightarrow$ listening & 0.08 & 0.55 \\
\hline reading $\rightarrow$ WARP & 0.80 & $<0.001$ & intelligence $\rightarrow$ listening & 0.24 & 0.17 \\
\hline reading $\rightarrow$ NAPLAN Reading & 0.88 & $<0.001$ & $\mathrm{ddt} \rightarrow$ listening & 0.60 & 0.47 \\
\hline$(\mathrm{DDT}-\mathrm{L}) \curvearrowleft($ FPT-L) & 0.13 & 0.60 & $\mathrm{fpt} \rightarrow$ listening & -0.04 & 0.78 \\
\hline$(\mathrm{DDT}-\mathrm{R}) \curvearrowleft($ FPT-R $)$ & 0.26 & 0.003 & gin $\rightarrow$ listening & -0.04 & 0.68 \\
\hline$(\mathrm{DDT}-\mathrm{L}) \curvearrowleft(\mathrm{GIN}-\mathrm{L})$ & -0.32 & 0.81 & lisn $\rightarrow$ listening & -0.13 & 0.60 \\
\hline$(\mathrm{DDT}-\mathrm{R}) \curvearrowleft(\mathrm{GIN}-\mathrm{R})$ & 0.07 & 0.54 & memory $\rightarrow$ reading & 0.56 & $<0.001$ \\
\hline$($ FPT-L) $\leadsto($ GIN-L $)$ & -0.43 & 0.81 & attention $\rightarrow$ reading & 0.33 & 0.001 \\
\hline$(\mathrm{FPT}-\mathrm{R}) \curvearrowleft(\mathrm{GIN}-\mathrm{R})$ & -0.02 & 0.86 & intelligence $\rightarrow$ reading & 0.20 & 0.02 \\
\hline (Teacher quest.) $\leadsto$ (WARP) & 0.48 & $<0.001$ & listening $\rightarrow$ reading & 0.12 & 0.23 \\
\hline memory $\curvearrowright$ attention & 0.44 & $<0.001$ & & & \\
\hline memory $\leadsto$ intelligence & 0.47 & $<0.001$ & & & \\
\hline attention $\leadsto$ intelligence & 0.25 & 0.003 & & & \\
\hline
\end{tabular}


Table 4: Test statistics and p-values for the tests of the combined effect of the auditory processing variables and the combined effect of the cognitive variables in the simplified models (Figure 3 and Supplemental Digital Content 4).

\begin{tabular}{lcc}
\hline Set of variables tested & Listening & Reading \\
\hline ddt, fpt, gin, lisn & $\chi_{4}^{2}=1.1 ; p=0.90$ & $\chi_{4}^{2}=2.1 ; p=0.72$ \\
memory, attention, intelligence & $\chi_{3}^{2}=12.7 ; p=0.005$ & $\chi_{3}^{2}=21.6 ; p<0.001$ \\
\hline
\end{tabular}


Supplemental Digital Content 1 for "The relations between auditory processing scores and cognitive, listening and reading abilities" by Mark Seeto, Dani Tomlin and Harvey Dillon.

The questionnaire completed by the parent is shown below. On the basis of item-total correlations, items 1, 2, 6, 18, 20 and 21 were not included in the overall parent questionnaire score used in this study.

\section{FISHER'S AUDITORY PROBLEMS CHECKLIST}

Student Name District/Building

Date. Grade Observer Position

Please place a check mark before each item that is considered to be a concern by the observer:

1. Has a history of hearing loss.

2. Has a history of ear infection(s).

3. Does not pay attention (listen) to instruction $50 \%$ or more of the time.

- 4. Does not listen carefully to directions - often necessary to repeat instructions.

_ 5. Says "Huh?" and "What?" at least five or more times per day.

6. Cannot attend to auditory stimuli for more than a few seconds.

7. Has a short attention span. (if this item is checked, 0-2 minutes 5-15 minutes also check the most appropriate time frame.) 2-5 minutes 15-30 minutes

8. Daydreams - attention drifts - not with it at times.

- 9. Is easily distracted by background sound(s).

10. Has difficulty with phonics.

11. Experiences problems with sound discrimination.

12. Forgets what is said in a few minutes.

13. Does not remember simple routine things from day to day.

14. Displays problems recalling what was heard last week, month, year.

15. Has difficulty recalling a sequence that has been heard.

_ 16. Experiences difficulty following auditory directions.

17. Frequently misunderstands what is said.

18. Does not comprehend many words - verbal concepts for age/grade level.

19. Learns poorly through the auditory channel.

20. Has a language problem (morphology, syntax, vocabulary, phonology).

_ 21. Has an articulation (phonology) problem.

22. Cannot always relate what is heard to what is seen.

_ 23. Lacks motivation to learn.

24. Displays slow or delayed response to verbal stimuli.

- 25. Demonstrates below average performance in one or more academic area(s).

Scoring: Four percent credit for each numbered item not checked.

Number of items not checked __ $\times 4=$

Normative data - grade score from reverse side

(C) All Printing Rights Reserved 
The questionnaire completed by the teacher is shown below. All items were included in the overall teacher questionnaire score used in this study.

\section{Teacher Evaluation of Auditory Performance (TEAP)}

Adapted from questionnaires by Sanger et al. (1987) \& Smoski et al. (1992) - see PURDY, S.C., KELLY, A.S., DAVIES, M.G., Auditory brainstem response, middle latency response, and late cortical evoked potentials in children with learning disabilities. Journal of the American Academy of Audiology, 13, 367-382, 2002.

Please rate this child's behaviour compared to other children of similar age and background.

SECTION A. RESPONSE CHOICES

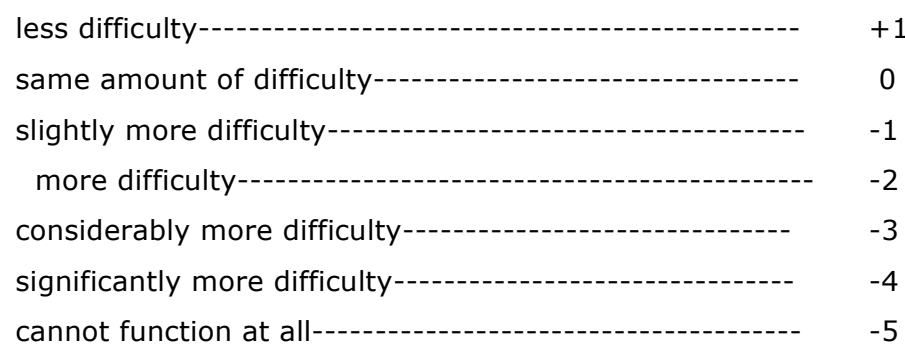

A1. If listening in a room where there is background noise such as others talking, children playing etc., this child has difficulty hearing and understanding

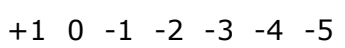

A2. If listening in a quiet room (others may be present, but are being quiet), this child has difficulty hearing and understanding

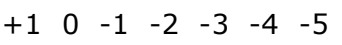

A3. When listening in ideal conditions (quiet room, no distractions, face-to-face, good eye contact) this child has difficulty hearing and understanding

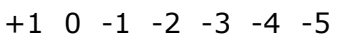

A4. This child has difficulty following multistage oral instructions $\begin{array}{lllllll}1 & 0 & -1 & -2 & -3 & -4 & -5\end{array}$

A5. This child has difficulty maintaining concentration/attention when background noise is present.

$$
\begin{array}{lllllll}
+1 & 0 & -1 & -2 & -3 & -4 & -5
\end{array}
$$

A6. This child has difficulty maintaining concentration/attention in ideal listening conditions

$$
\begin{array}{lllllll}
+1 & 0 & -1 & -2 & -3 & -4 & -5
\end{array}
$$

A7. This child has difficulty completing tasks or answering questions within a reasonable time frame. 
The questionnaire completed by the child is shown below, over two pages. On the basis of item-total correlations, item 5 was not included in the overall child questionnaire score used in this study.

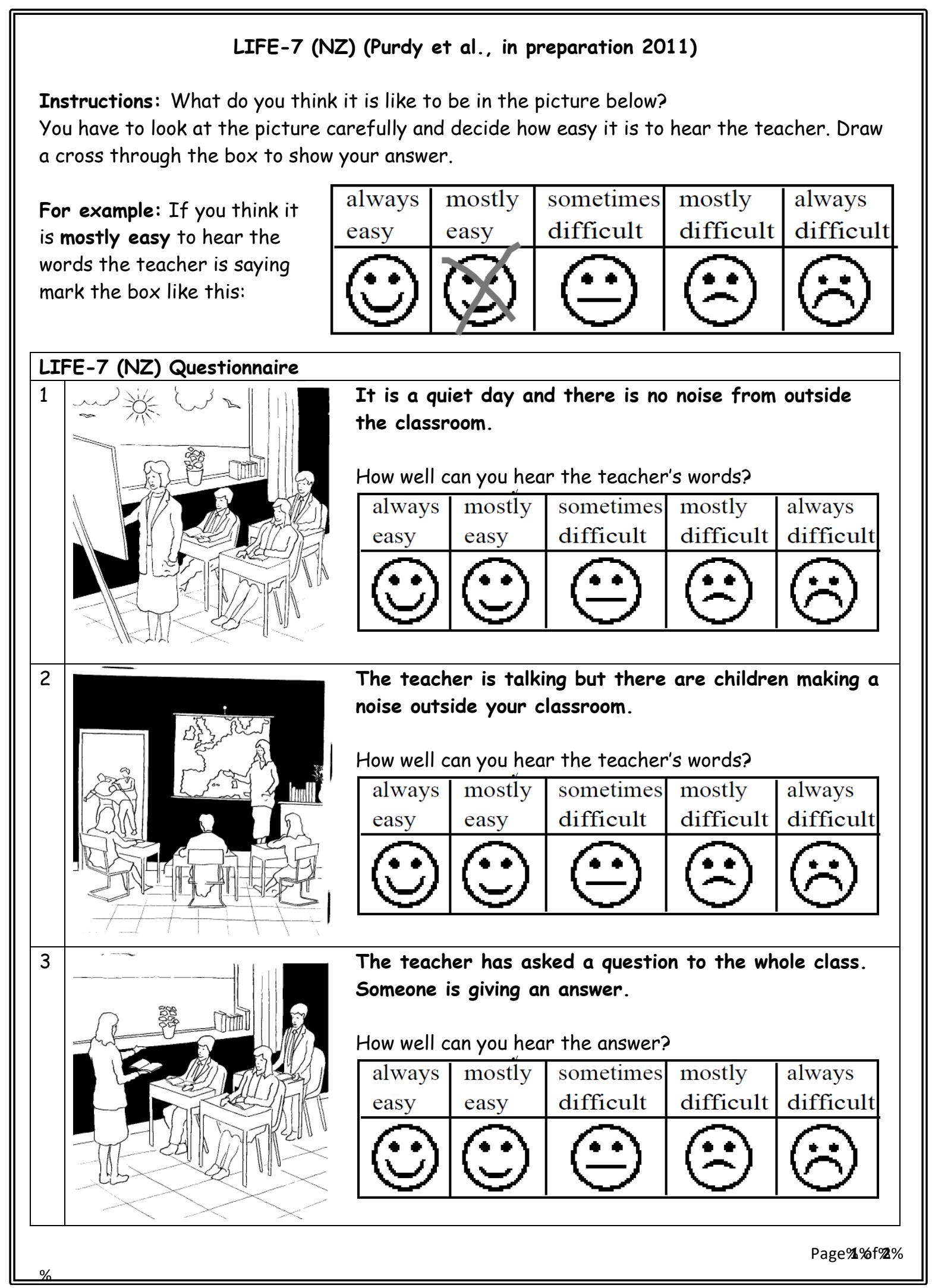




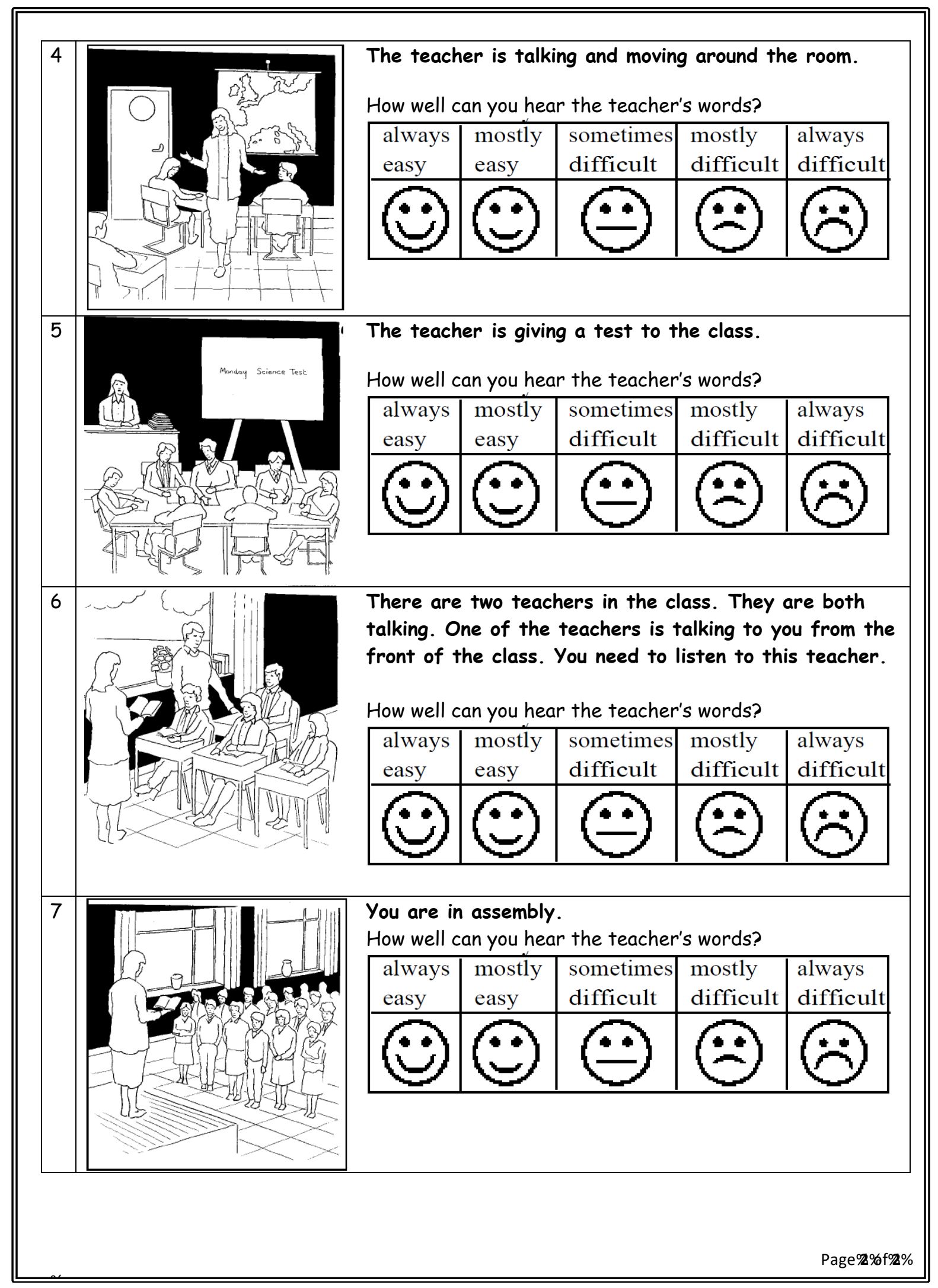


Supplemental Digital Content 2 for "The relations between auditory processing scores and cognitive, listening and reading abilities" by Mark Seeto, Dani Tomlin and Harvey Dillon.

Table S2a: Descriptive statistics for the observed variables on their original scales. Abbreviations for the variables are explained in Table 1 in the article. The abbreviations in the headings are "SD" for standard deviation, "Min." for minimum, and "Max." for maximum. The range is the maximum minus the minimum. The DS-Fwd and DS-Rev scaled scores have normative mean of 10 and normative standard deviation of 3, and the CPT-Aud, CPT-Vis and TONI quotient scores have normative mean of 100 and normative standard deviation of 15 . For GIN-L, GIN-R, LISN-LC, LISN-HC and the child questionnaire, lower values indicate better performance, while for the other measures, higher values indicate better performance. The questionnaire scores do not include the items that were removed.

\begin{tabular}{lrrrrrr}
\hline Variable & Mean & SD & Median & Min. & Max. & Range \\
\hline DDT-L (percent correct) & 77.5 & 15.1 & 82.5 & 32.0 & 100.0 & 68.0 \\
DDT-R (percent correct) & 85.2 & 11.7 & 87.5 & 20.0 & 100.0 & 80.0 \\
FPT-L (percent correct) & 65.7 & 26.9 & 73.0 & 0.0 & 100.0 & 100.0 \\
FPT-R (percent correct) & 66.8 & 27.8 & 73.0 & 0.0 & 100.0 & 100.0 \\
GIN-L (shortest gap in milliseconds) & 5.1 & 1.1 & 5.0 & 3 & 10 & 7 \\
GIN-R (shortest gap in milliseconds) & 5.1 & 1.2 & 5.0 & 3 & 10 & 7 \\
MLD (SNR difference in dB) & 11.7 & 2.6 & 12.0 & 6 & 18 & 12 \\
LISN-LC (SNR in dB) & -0.2 & 1.3 & -0.3 & -3.7 & 8.0 & 11.7 \\
LISN-HC (SNR in dB) & -12.5 & 4.8 & -13.1 & -19.5 & 15.1 & 34.6 \\
DS-Fwd (scaled score) & 9.4 & 2.5 & 9.0 & 3 & 19 & 16 \\
DS-Rev (scaled score) & 9.4 & 2.3 & 9.0 & 5 & 15 & 10 \\
CPT-Aud (quotient score) & 78.8 & 31.6 & 89.5 & 0 & 125 & 125 \\
CPT-Vis (quotient score) & 91.2 & 21.9 & 97.0 & 0 & 124 & 124 \\
TONI (quotient score) & 103.5 & 9.2 & 102.0 & 84 & 128 & 44 \\
Parent quest. (number of items not indicated) & 13.1 & 4.8 & 14.0 & 1 & 19 & 18 \\
Teacher quest. (sum; each item -5 to +1) & -7.2 & 9.1 & -8.0 & -26 & 7 & 33 \\
Child quest. (sum; each item 1 to 5) & 13.5 & 4.5 & 13.0 & 6 & 27 & 21 \\
WARP (correct words per minute) & 102.6 & 49.1 & 108.5 & 2 & 200 & 198 \\
NAPLAN Reading (achievement score) & 466.4 & 78.8 & 480.0 & 230 & 625 & 395 \\
\hline
\end{tabular}

Table S2b: Descriptive statistics for the observed variables on the z-score scale. For all measures, higher z-scores indicate better performance.

\begin{tabular}{lrrrrrc}
\hline Variable (z-score) & Mean & SD & Median & Min. & Max. & Range \\
\hline DDT-L & -1.16 & 1.62 & -0.94 & -5.75 & 2.13 & 7.88 \\
DDT-R & -0.52 & 1.21 & -0.55 & -5.95 & 2.58 & 8.54 \\
FPT-L & -0.72 & 1.53 & -0.61 & -5.06 & 2.27 & 7.33 \\
FPT-R & -0.62 & 1.63 & -0.59 & -4.98 & 2.03 & 7.00 \\
GIN-L & -0.09 & 1.13 & 0.00 & -5.00 & 2.00 & 7.00 \\
GIN-R & -0.07 & 1.15 & 0.00 & -5.00 & 2.00 & 7.00 \\
MLD & 0.17 & 1.16 & 0.24 & -2.06 & 3.27 & 5.33 \\
LISN-LC & -0.38 & 0.83 & -0.30 & -2.60 & 2.10 & 4.70 \\
LISN-HC & -0.41 & 0.99 & -0.40 & -4.10 & 2.50 & 6.60 \\
DS-Fwd & -0.19 & 0.84 & -0.33 & -2.33 & 3.00 & 5.33 \\
DS-Rev & -0.22 & 0.76 & -0.33 & -1.67 & 1.67 & 3.33 \\
CPT-Aud & -1.42 & 2.11 & -0.70 & -6.67 & 1.67 & 8.33 \\
CPT-Vis & -0.59 & 1.46 & -0.20 & -6.67 & 1.60 & 8.27 \\
TONI & 0.24 & 0.61 & 0.13 & -1.07 & 1.87 & 2.93 \\
WARP & -0.17 & 1.07 & -0.17 & -2.70 & 2.12 & 4.82 \\
NAPLAN Reading & 0.27 & 0.93 & 0.46 & -2.45 & 1.76 & 4.20 \\
\hline & & & & & &
\end{tabular}


Supplemental Digital Content 3 for "The relations between auditory processing scores and cognitive, listening and reading abilities" by Mark Seeto, Dani Tomlin and Harvey Dillon.

Table S3: Pearson correlations of the auditory processing and cognitive z-scores (with pairwise deletion of missing data), and p-values for the tests of the null hypotheses that the true correlation values are zero. Within each set of three rows, the first row $(r)$ is the sample correlation value, the second row $(p)$ is the unadjusted p-value, and the third row $\left(p_{A}\right)$ is the Holm-Bonferroni adjusted p-value. For each pair of variables, a positive correlation indicates that in this sample, improved performance on one measure was associated with improved performance on the other measure. Abbreviations for the variables are explained in Table 1 in the article.

\begin{tabular}{|c|c|c|c|c|c|c|c|c|c|c|c|c|c|c|c|}
\hline & & 皇 & 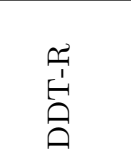 & 预 & 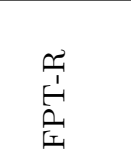 & 莣 & 党 & $\stackrel{\ominus}{\stackrel{9}{g}}$ & 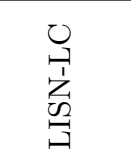 & 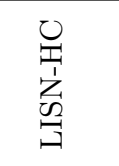 & 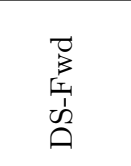 & 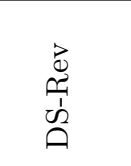 & 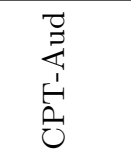 & 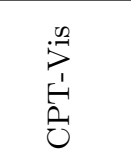 & $\underset{H}{n}$ \\
\hline \multirow{3}{*}{ DDT-L } & $r$ & 1.00 & 0.38 & 0.33 & 0.27 & 0.04 & 0.08 & -0.07 & 0.24 & 0.18 & 0.43 & 0.39 & 0.18 & 0.28 & 0.38 \\
\hline & $p$ & & $<0.001$ & $<0.001$ & $<0.001$ & 0.65 & 0.32 & 0.38 & 0.002 & 0.02 & $<0.001$ & $<0.001$ & 0.04 & 0.002 & $<0.001$ \\
\hline & $p_{A}$ & & $<0.001$ & 0.003 & 0.05 & 1.00 & 1.00 & 1.00 & 0.15 & 1.00 & $<0.001$ & $<0.001$ & 1.00 & 0.15 & $<0.001$ \\
\hline \multirow{3}{*}{ DDT-R } & $r$ & 0.38 & 1.00 & 0.26 & 0.31 & 0.07 & 0.10 & -0.12 & 0.21 & 0.11 & 0.36 & 0.34 & 0.16 & 0.16 & 0.28 \\
\hline & $p$ & $<0.001$ & & $<0.001$ & $<0.001$ & 0.39 & 0.24 & 0.15 & 0.01 & 0.18 & $<0.001$ & $<0.001$ & 0.07 & 0.07 & $<0.001$ \\
\hline & $p_{A}$ & $<0.001$ & & 0.06 & 0.006 & 1.00 & 1.00 & 1.00 & 0.57 & 1.00 & $<0.001$ & 0.001 & 1.00 & 1.00 & 0.04 \\
\hline \multirow{3}{*}{ FPT-L } & $r$ & 0.33 & 0.26 & 1.00 & 0.91 & 0.18 & 0.15 & 0.00 & 0.13 & 0.08 & 0.26 & 0.38 & 0.17 & 0.11 & 0.43 \\
\hline & $p$ & $<0.001$ & $<0.001$ & & $<0.001$ & 0.03 & 0.07 & 0.98 & 0.10 & 0.31 & 0.001 & $<0.001$ & 0.06 & 0.22 & $<0.001$ \\
\hline & $p_{A}$ & 0.003 & 0.06 & & $<0.001$ & 1.00 & 1.00 & 1.00 & 1.00 & 1.00 & 0.09 & $<0.001$ & 1.00 & 1.00 & $<0.001$ \\
\hline \multirow{3}{*}{ FPT-R } & $r$ & 0.27 & 0.31 & 0.91 & 1.00 & 0.21 & 0.16 & -0.01 & 0.12 & 0.14 & 0.23 & 0.33 & 0.13 & 0.05 & 0.41 \\
\hline & $p$ & $<0.001$ & $<0.001$ & $<0.001$ & & 0.008 & 0.05 & 0.89 & 0.14 & 0.08 & 0.005 & $<0.001$ & 0.13 & 0.58 & $<0.001$ \\
\hline & $p_{A}$ & 0.05 & 0.006 & $<0.001$ & & 0.48 & 1.00 & 1.00 & 1.00 & 1.00 & 0.29 & 0.002 & 1.00 & 1.00 & $<0.001$ \\
\hline \multirow{3}{*}{ GIN-L } & $r$ & 0.04 & 0.07 & 0.18 & 0.21 & 1.00 & 0.80 & -0.02 & 0.05 & 0.16 & 0.08 & 0.05 & 0.11 & -0.04 & 0.12 \\
\hline & $p$ & 0.65 & 0.39 & 0.03 & 0.008 & & $<0.001$ & 0.85 & 0.52 & 0.05 & 0.35 & 0.58 & 0.21 & 0.69 & 0.16 \\
\hline & $p_{A}$ & 1.00 & 1.00 & 1.00 & 0.48 & & $<0.001$ & 1.00 & 1.00 & 1.00 & 1.00 & 1.00 & 1.00 & 1.00 & 1.00 \\
\hline \multirow{3}{*}{ GIN-R } & $r$ & 0.08 & 0.10 & 0.15 & 0.16 & 0.80 & 1.00 & -0.05 & 0.02 & 0.08 & 0.09 & 0.03 & 0.07 & 0.01 & 0.14 \\
\hline & $p$ & 0.32 & 0.24 & 0.07 & 0.05 & $<0.001$ & & 0.57 & 0.82 & 0.33 & 0.26 & 0.71 & 0.41 & 0.92 & 0.09 \\
\hline & $p_{A}$ & 1.00 & 1.00 & 1.00 & 1.00 & $<0.001$ & & 1.00 & 1.00 & 1.00 & 1.00 & 1.00 & 1.00 & 1.00 & 1.00 \\
\hline \multirow{3}{*}{ MLD } & $r$ & -0.07 & -0.12 & 0.00 & -0.01 & -0.02 & -0.05 & 1.00 & -0.05 & -0.08 & 0.15 & -0.05 & -0.06 & -0.01 & 0.07 \\
\hline & $p$ & 0.38 & 0.15 & 0.98 & 0.89 & 0.85 & 0.57 & & 0.58 & 0.36 & 0.07 & 0.57 & 0.52 & 0.90 & 0.41 \\
\hline & $p_{A}$ & 1.00 & 1.00 & 1.00 & 1.00 & 1.00 & 1.00 & & 1.00 & 1.00 & 1.00 & 1.00 & 1.00 & 1.00 & 1.00 \\
\hline \multirow{3}{*}{ LISN-LC } & $r$ & 0.24 & 0.21 & 3 & 0.12 & 0.05 & 0.02 & -0.05 & 1.00 & 0.24 & 0.27 & 0.18 & 0.04 & 0.00 & 0.28 \\
\hline & $p$ & 0.002 & 0.01 & 0.10 & 0.14 & 0.52 & 0.82 & 0.58 & & 0.003 & $<0.001$ & 0.02 & 0.65 & 1.00 & $<0.001$ \\
\hline & $p_{A}$ & 0.15 & 0.57 & 1.00 & 1.00 & 1.00 & 1.00 & 1.00 & & 0.20 & 0.04 & 1.00 & 1.00 & 1.00 & 0.04 \\
\hline \multirow{3}{*}{ LISN-HC } & $r$ & 0.18 & 0.11 & 0.08 & 0.14 & 0.16 & 0.08 & -0.08 & 0.24 & 1.00 & 0.12 & 0.11 & 0.20 & 0.02 & 0.22 \\
\hline & $p$ & 0.02 & 0.18 & 0.31 & 0.08 & 0.05 & 0.33 & 0.36 & 0.003 & & 0.14 & 0.16 & 0.02 & 0.86 & 0.009 \\
\hline & $p_{A}$ & 1.00 & 1.00 & 1.00 & 1.00 & 1.00 & 1.00 & 1.00 & 0.20 & & 1.00 & 1.00 & 1.00 & 1.00 & 0.53 \\
\hline \multirow{3}{*}{ DS-Fwd } & $r$ & 0.43 & 0.36 & 0.26 & 0.23 & 0.08 & 0.09 & 0.15 & 0.27 & 0.12 & 1.00 & 0.47 & 0.16 & 0.12 & 0.31 \\
\hline & $p$ & $<0.001$ & $<0.001$ & 0.001 & 0.005 & 0.35 & 0.26 & 0.07 & 0.001 & 0.14 & & $<0.001$ & 0.08 & 0.21 & 0.001 \\
\hline & $p_{A}$ & $<0.001$ & $<0.001$ & 0.09 & 0.29 & 1.00 & 1.00 & 1.00 & 0.04 & 1.00 & & $<0.001$ & 1.00 & 1.00 & 0.008 \\
\hline \multirow{3}{*}{ DS-Rev } & $r$ & 0.39 & 0.34 & 0.38 & 0.33 & 0.05 & 3 & -0.05 & 0.18 & 0.11 & 0.47 & 1.00 & 0.39 & 0.29 & 0.32 \\
\hline & $p$ & $<0.001$ & $<0.001$ & $<0.001$ & $<0.001$ & 0.58 & 0.71 & 0.57 & 0.02 & 0.16 & $<0.001$ & & $<0.001$ & 0.001 & $<0.001$ \\
\hline & $p_{A}$ & $<0.001$ & 0.001 & $<0.001$ & 0.002 & 1.00 & 1.00 & 1.00 & 1.00 & 1.00 & $<0.001$ & & $<0.001$ & 0.08 & 0.006 \\
\hline \multirow{3}{*}{ CPT-Aud } & $r$ & 0.18 & 0.16 & 0.17 & 0.13 & 0.11 & 0.07 & -0.06 & 0.04 & 0.20 & 0.16 & 0.39 & 1.00 & 0.65 & 0.21 \\
\hline & $p$ & 0.04 & 0.07 & 0.06 & 0.13 & 0.21 & 0.41 & 0.52 & 0.65 & 0.02 & 0.08 & $<0.001$ & & $<0.001$ & 0.02 \\
\hline & $p_{A}$ & 1.00 & 1.00 & 1.00 & 1.00 & 1.00 & 1.00 & 1.00 & 1.00 & 1.00 & 1.00 & $<0.001$ & & $<0.001$ & 1.00 \\
\hline \multirow{3}{*}{ CPT-Vis } & $r$ & 0.28 & 0.16 & 0.11 & 0.05 & -0.04 & 0.01 & -0.01 & 0.00 & 0.02 & 0.12 & 0.29 & 0.65 & 1.00 & 0.22 \\
\hline & $p$ & 0.002 & 0.07 & 0.22 & 0.58 & 0.69 & 0.92 & 0.90 & 1.00 & 0.86 & 0.21 & 0.001 & $<0.001$ & & 0.01 \\
\hline & $p_{A}$ & 0.15 & 1.00 & 1.00 & 1.00 & 1.00 & 1.00 & 1.00 & 1.00 & 1.00 & 1.00 & 0.08 & $<0.001$ & & 0.85 \\
\hline \multirow{3}{*}{ TONI } & $r$ & 0.38 & 0.28 & 0.43 & 0.41 & 0.12 & 0.14 & 0.07 & 0.28 & 0.22 & 0.31 & 0.32 & 0.21 & 0.22 & 1.00 \\
\hline & $p$ & $<0.001$ & $<0.001$ & $<0.001$ & $<0.001$ & 0.16 & 0.09 & 0.41 & $<0.001$ & 0.009 & $<0.001$ & $<0.001$ & 0.02 & 0.01 & \\
\hline & $p_{A}$ & $<0.001$ & 0.04 & $<0.001$ & $<0.001$ & 1.00 & 1.00 & 1.00 & 0.04 & 0.53 & 0.008 & 0.006 & 1.00 & 0.85 & \\
\hline
\end{tabular}


Supplemental Digital Content 4 for "The relations between auditory processing scores and cognitive, listening and reading abilities" by Mark Seeto, Dani Tomlin and Harvey Dillon.

Figure S4: Simplified model for listening ability. Rectangles represent observed variables, ovals and circles represent latent variables, single-headed arrows represent causal effects, and double-headed arrows represent covariances. Unlabelled latent variables (circles) are error components. Abbreviations are explained in Table 1 in the article.

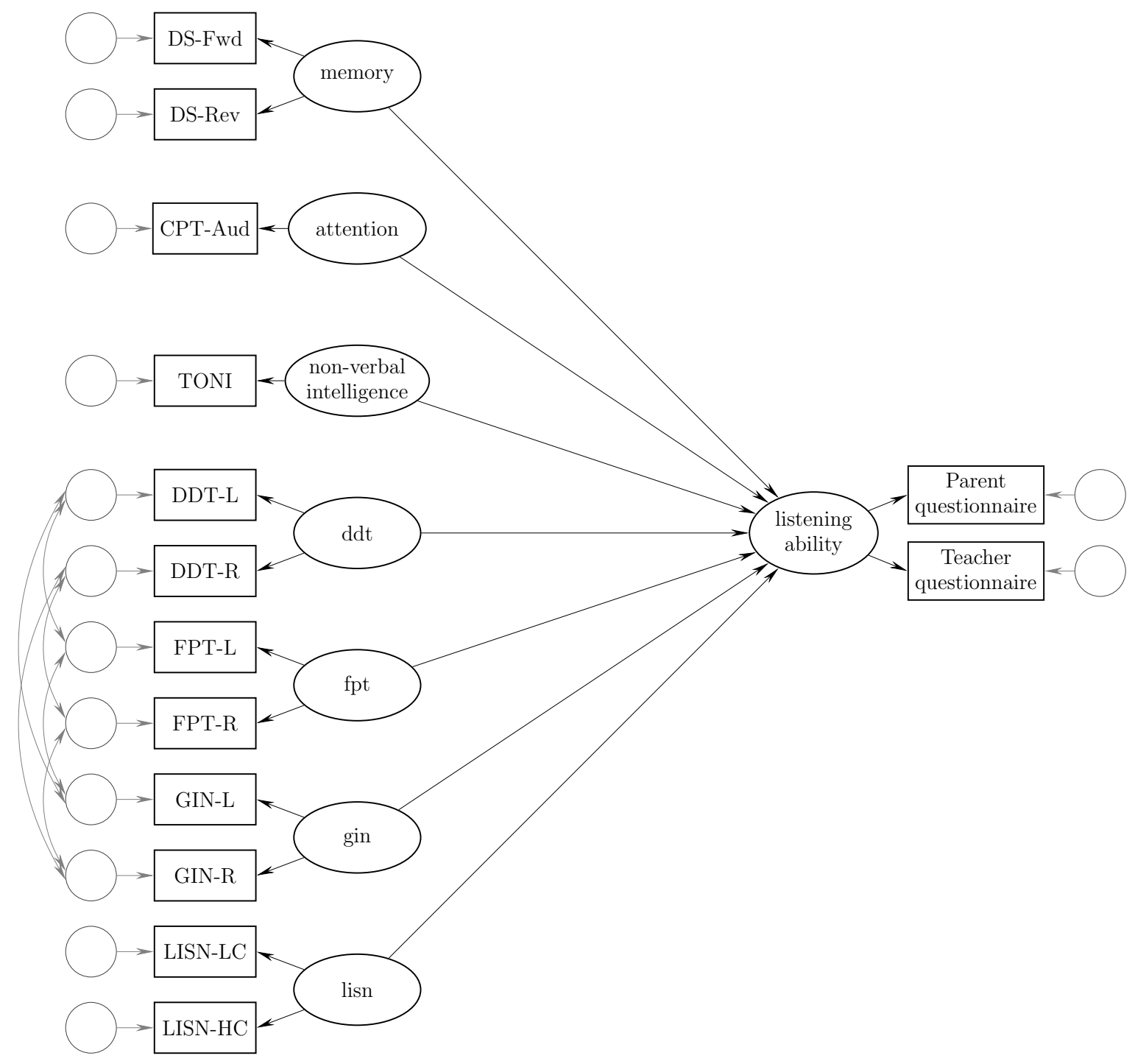

